\title{
Reflections on evolution
}

\section{Jackie Gunn}

Welcome to the 47th edition of the New Zealand College of Midwives (NZCOM) Journal. This edition marks a milestone in the Journal's history with a move to article based publishing. Last year the College decided that the Journal should change its format from a twice yearly, paper based printed issue, to an electronic article-based publication with an annual printed issue that aggregates the on-line papers.

In today's world there is a wealth of information readily available through the internet for health professionals and women and their families. Many journal publishers are recognising the need to provide faster access to research papers through an on-line service rather than expecting subscribers to wait for a fully printed edition to come in the post.

\section{WHAT IS ARTICLE BASED PUBLISHING?}

Essentially it is where each paper is published and disseminated electronically and contributes to an 'issue in progress' as soon as it has been approved for publication. This issue is then printed once it is completed.

There are significant advantages in article-based publication for both authors and readers. Authors do not face long delays in getting their research published, and therefore it is more readily available to practitioners, and readers have access to the latest research as soon as the peer review process is completed. Feedback to the journal editorial board to date suggests that our members are enjoying receiving the Journal articles in their email inboxes. However because not all members have access to good quality (or any) internet access, an annual publication that includes all the articles published on-line in the previous year is necessary. There are also many midwives and libraries who still prefer to have a fully printed paper version of the Journal.

\section{REFLECTING ON THE EVOLUTION OF THE JOURNAL}

The NZ College of Midwives Journal has been a feature of College membership since the foundation of the College in 1989 and has been published twice a year since 1989, this is an extraordinary accomplishment.

At the start, the Journal featured many of the practice stories, commentary and information that are now published in the Midwifery News. The 15th issue in October 1996 for example, included one research article by Orma Bradfield, and papers, addresses and the NZCOM president's report from the 1996 National Conference. The content of Issue 15 reflects how little research was being undertaken by New Zealand midwives at that time. The strategic decision taken right at the beginning of the NZCOM Journal's life, that it would publish peer reviewed research of international quality, continues to pay dividends. The vision was, and is, for an internationally recognised midwifery research journal. As this vision developed, and more midwifery research was being undertaken, the NZCOM National Newsletter evolved into the Midwifery News and the Journal became more focussed on publishing research articles as primary content.

One of the quality hallmarks for published research papers is that all the research papers are blind peer reviewed by two reviewers. Peer review means that the papers have been quality reviewed by more than one person on the Journal's review panel. It is a tribute to the quality and commitment of a long line of Journal reviewers that their feedback and support have helped so many authors to publish their papers.

The next milestone was to make the Journal available to a wider group. In 2003 the journal became indexed on the CINAHL (Cumulative Index to Nursing and Allied Health Literature) database which ensured that published papers were listed and available to a wider international audience of researchers. At the same time and due to the development of the NZCOM website journal articles could be accessed electronically with each issue of the Journal available through the College website (six months after initial publication so that members retained primary access as a membership privilege). With the introduction of article-based publication and the DOI numbers the on-line publication has now reduced to 3 months. Additionally as a means of increasing the Journals' international visibility, listing in other databases is currently being explored.

Over the years, passionate and committed midwives have served the Journal extremely well as editors. Their commitment and passion has ensured the continuous evolution (and publication!) of the NZCOM Journal. Editors ensure that papers are reviewed and prepared for publication, and put each issue to the publishers. The College of Midwives owes its editors a great debt for their commitment to the Journal and the College's vision for it. Helen Manoharan, from Palmerston North, was the original editor for a number of years. She was followed by the editorial board from Otago Polytechnic Midwifery School of Alison Stewart, Rhondda Davies, Deborah Davis, Jean Patterson and Sally Pairman. Joan Skinner from VUW, Graduate School of Midwifery, held the position next. She was joined by Lesley Dixon from NZCOM national office who manages the secretariat work for each issue. The current editors, Lesley Dixon and Andrea Gilkison, from AUT University, Dept. of Midwifery, with the editorial team follow very capably in their predecessors' footsteps.

Looking back over the course of more than 25 years that I have been involved in midwifery education and research at AUT University, it is wonderful to see how both midwifery and midwives' research capacity has evolved. In 1989, midwifery education was on the threshold of transition from hospital based, task focused training, to tertiary education based, and research focused education for practice. The evolution of degree level preregistration programmes and more latterly, post graduate midwifery education opportunities has resulted in the continuing development of research-capable midwives. The midwives who have embraced on-going midwifery education and research are tomorrow's leaders, educators and researchers. The recent advent of funded postgraduate education for midwives has given another boost to capacity building for the future.

The profession must always be preparing people for the future which is a theme reflected in this issue. The changing face of education is the focus of Andrea Gilkison's paper which maps the many extrinsic and societal factors that have influenced midwifery undergraduate education in New Zealand. It is always important to know our history when we are making changes and preparing for the future. In the same vein Liz James has examined the experiences of a small group of midwives who have worked with third year midwifery students. By exploring the relationship between the midwife and the student Liz found that a positive trusting relationship was central to the learning experience for both. In many ways this mirrors the partnership relationship that underpins midwifery practice and supports women's preparation for parenting. Women who have become pregnant following assisted reproductive technologies are the focus of a literature review undertaken by Lynley Allot and colleagues who have identified the issues midwives need to consider when providing care for these women. While the importance of the midwife 'knowing' the woman is highlighted by a small group of university students in Lisa Newicks paper which used focus groups to identify student views about midwifery and maternity services.

The Journal is at a turning point in its development. The number and quality of papers being submitted for publication is steadily increasing as New Zealand based midwifery research increases. There is a healthy number of papers in the review pipeline, so keep an eye on your inbox. The Journal has always encouraged midwives to send papers for publication and it is exciting to see the expansion of local midwifery research reflected in the papers being submitted. 